Estimate for the Maximum

Compression of Single Shocks

J. D. Johnson



OSTAMUTION OF THIS DOCUMENT IS INIMTEB

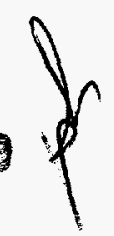




\section{DISCLAIMER}

This report was prepared as an account of work sponsored by an agency of the United States Government. Neither the United States Government nor any agency thereof, nor any of their employees, make any warranty, express or implied, or assumes any legal liabii. ty or responsibility for the accuracy, completeness, or usefulness of any information, apparatus, product, or process disclosed, or represents that its use would not iniringe privately owned rights. Reference herein to any specific commercial product, process, or service by trade name, trademark, manufacturer, or otherwise does not necessarily constitute or imply its endorsement, recommendation, or favoring by the United States Government or any agency thereof. The views and opinions of authors expressed herein do not necessarily state or reflect those of the United States Government or any agency thereof. 


\section{DISCLAIMER}

Portions of this document may be illegible electronic image products. Images are produced from the best available original document. 


\title{
ESTIMATE FOR THE MAXIMUM COMPRESSION \\ OF SINGLE SHOCKS
}

J. D. Johnson

\begin{abstract}
We derive that the maximum compression for any single-shock Hugoniot has an upper bound of 7. For the principal Hugoniot, we present a simple analytic estimate for the maximum compression as a function of $\rho_{o}$ (initial density), $A$ (atomic weight), $Z$ (atomic number), and $\Delta E$ (the sum of cohesion, dissociation, and total ionization energies).
\end{abstract}

An Upper Bound

Any Hugoniot is determined from the hydrodynamic equation of state $P(\rho, E)$ and the energy jump condition,

$$
E-E_{o}=\frac{1}{2}\left(P+P_{o}\right)\left(1 / \rho_{o}-1 / \rho\right) .
$$

Here $P$ is pressure, $\rho$ is density, and $E$ is the internal energy per gram. $P_{o}, \rho_{o}$, and $E_{o}$ represent the same but are for the initial state of the Hugoniot. We define the compression as $\eta=\rho / \rho_{o}$ and rewrite Eq. (1) as

$$
\eta=4+\left[2 \rho\left(E-E_{o}\right)-3\left(P+P_{o}\right)\right] /\left(P+P_{o}\right)
$$


We now assume that the virial theorem is exact for the equation of state [1]; i.e., if $E=K+U$, where $K$ is the average kinetic energy per gram and $U$ is the average potential energy per gram, then $P / \rho=2 K / 3+U / 3$. (We are considering here the case of physical interest, namely, the charge neutral, quantum coulomb system.) It is widely believed that this assumption is true, although there is no rigorous proof in the literature. Substituting into Eq. (2), we get

$$
\eta=\eta_{b}-3 P_{o}(1+\eta) /\left(P+P_{o}\right) \leq \eta_{b}
$$

where $\eta_{b}=4+\rho\left(U-U_{o}\right) /\left(P+P_{o}\right)$. If $U \leq U_{o}$, then $\eta \leq \eta_{b} \leq 4$. If $U \geq U_{o}$, then we rewrite Eq. (3) as

$$
\eta \leq \eta_{b}=4+3 /\left[1+2 K_{s} / U_{s}+3 P_{o}\left(1 / \rho+1 / \rho_{o}\right) / U_{s}\right],
$$

where $K_{s}=K-K_{o}$ and $U_{s}=U-U_{o}$.

For classical systems, $K_{s} \geq 0$ because the average kinetic energy is linear in temperature $T$. For quantum systems, we can only say that it is very reasonable that $K_{s} \geq 0$ when $U_{s} \geq 0$ if $\eta \geq 7-\varepsilon \quad(\varepsilon>0)$. (Models support this position.) Then from Eq. (4), $\eta \leq \eta_{b} \leq 7$. Thus we conclude that the compression along a single-shock Hugoniot for any material cannot exceed 7 .

An Estimate for the Principal Hugoniot

We now look to the principal Hugoniot, where $P_{o}=0$. We assume that we are shocking from $T=0$. (The difference between zero and room temperature is small when we are looking for estimates of the maximum compression.) From Eqs. (3) and (4), we find that 


$$
\eta=4+3 /\left(1+2 K_{s} / U_{s}\right)
$$

It is convenient to define $Y=\frac{1}{2} U_{s} / \Delta E$ where, for the principal Hugoniot, $\Delta E=-E_{o}$ and is the sum of cohesive, dissociation, and total ionization energies. Then

$$
\eta=\left(7 Y+4 K_{s} / \Delta E\right) /\left(Y+K_{s} / \Delta E\right)
$$

From the exact high-temperature series for the equation of state of any elemental material [2], we obtain $Y$ as an exact series in $1 / K_{s}$. (We are thinking of $K_{s}$ as the independent variable.) All that we need is

$$
Y=1+a \alpha^{1 / 2}+\cdots
$$

with

$$
a=-e^{3}(1+Z)^{2}(L / A)^{2} / \Delta E
$$

and

$$
\alpha=\frac{3}{2} \pi Z^{3} \rho_{o} / K_{s}
$$

In these equations, $L$ is Avogadro's number, and $e$ is the electron charge. The $a \alpha^{1 / 2}$ originates from the Debye-Hückel term in the high $-T$ expansion.

We substitute Eqs. (7a)-(7c) into Eq. (6) and solve for the maximum compression, $\eta_{m}$. The result is

$$
\eta_{m}=4(1+7 C) /(1+4 C)
$$

with

$$
C=2(\Delta E / Z)^{3} A^{4} /\left[81 e^{6} \pi(1+Z)^{4} L^{4} \rho_{o}\right]
$$


This is our estimate for the maximum compression along the principal Hugoniot.

Equation (8b) can be simplified further if one neglects cohesive and dissociation energies. We fit to the total ionization energies of C. E. Moore (through Ca) [3] to estimate that $\Delta E \equiv 13.6 Z^{2.4}$ ev per atom. Thus

$$
C \cong 0.011 A Z^{4.2} /\left[\rho_{o}(1+Z)^{4}\right]
$$

Conclusions

The estimates of Eqs. (8a)-(8c) and an upper bound of 7 are our results. The only data on $\eta_{m}$ is for Al [4]. There $\eta_{m} \sim 5$, and that value agrees well with Eqs. (8). One has available more terms in the expansion Eq. (7a). We have extensively studied these terms and found that they do not influence our estimates at all. We have also extensively worked with the series Eq. (7a) using Padé approximants. Again there was no influence at all. We feel Eqs. (8a)-(8c) are a quite good approximation of $\eta_{m}$. The Al data, models, and Eqs. (8) all show that the bound of 7 is a tight one, with some materials having an $\eta_{m}$ of about 6 . 
References

[1] See, for example, J. O. Hirschfelder, C. F. Curtiss, and R. B. Bird, Molecular Theory of Gases and Liquids (John Wiley \& Sons, Inc., New York, 1954), p. 398.

[2] See, for example, A. L. Fetter and J. D. Walecka, Quantum Theory of Many-Particle Systems (McGraw-Hill, Inc., New York, 1971) p. 267.

[3] C. E. Moore, "Ionization Potentials and Ionization Limits Derived from the Analysis of Optical Spectra," Nat. Stand. Ref. Data Ser., Nat. Bur. Stand. (U.S.), 35 (1970).

[4] A. S. Vladimirov, N. P. Voloshin, V. N. Nogin, A. V. Petrovtsev, and V. A. Simonenko, Sov. Phys. JETP Lett. $\underline{39}, 85$ (1984). 